DOI: 10.18554/cimeac.v7i1.2215

\title{
APRESENTAÇÃO \\ Educação e povos indígenas: debates e práticas interculturais
}

Daniela Bueno de Oliveira Américo de Godoy*

O dossiê "Educação e povos indígenas: debates e práticas interculturais" compõe o primeiro número de 2017 da revista Cadernos CIMEAC. Trata-se de uma produção que visa abordar, de diferentes pontos de vista, questões indígenas próprias ao cenário educacional atual no Brasil e na América Latina. A partir das tensões relativas aos encontros entre diferentes epistemologias, ontologias e pedagogias, o principal objetivo dessa obra é apresentar o campo da educação intercultural como uma arena dialógica privilegiada para a promoção de profundas transformações sociais. Espera-se que o debate gerado pela participação de povos indígenas nos vários níveis da educação formal possa propiciar reflexões que extrapolem o âmbito aparentemente restritivo concernente à educação indígena, sem, contudo, desqualificar mecanismos necessários à afirmação de diferenças.

Com o intuito de introduzir as temáticas apresentadas na entrevista e nos nove artigos desse dossiê, considera-se importante destacar o protagonismo dos povos indígenas para a garantia da educação intercultural e bilíngue, conforme assegurada pela Constituição Federal de 1988, posteriormente ampliada na forma das licenciaturas interculturais; e mais recentemente, pelo acesso a cursos regulares na educação superior. Essa realidade além de requerer políticas públicas de ações afirmativas capazes não apenas de inserir, mas de manter esses estudantes nessas instituições também atesta que essas conquistas carregam consigo contradições e novos desafios às concepções autóctones de educação.

\footnotetext{
* Doutorado em Psicologia pela Universidade de São Paulo (USP), com estágio de pós-doutorado pela mesma instituição. Organizadora do dossiê "Educação e povos indígenas: debates e práticas interculturais" (Cadernos CIMEAC, 2017).
} 
Os diversos temas tratados versam sobre práticas interculturais em educação, seja pela apresentação de experiências próprias a situações de ensino formal em contextos de diversidade, seja por meio de reflexões, críticas e propostas ao modelo de educação diferenciada vigente para os povos indígenas. Uma leitura possível desses textos compreende o anseio ameríndio em direção à escolarização em função de um duplo movimento: a necessidade de apropriação de tecnologias exteriores a seus modos de vida tradicionais e, ao mesmo tempo, o desejo de afirmação de suas especificidades e demandas diante do mundo ocidental. Os artigos presentes nessa edição são contribuições oriundas da Colômbia e de diferentes regiões do Brasil.

O texto de abertura desse dossiê é uma entrevista concedida pelo professor indígena (baniwa) Gersem José dos Santos Luciano. Filósofo, mestre e doutor em antropologia social, é atualmente docente na UFAM. Liderança indígena militante, atuou também junto a diversas instâncias do governo (municipal e federal) dentre as quais Conselheiro do Conselho Nacional de Educação e Coordenador Geral de Educação Escolar Indígena do Ministério da Educação. A entrevista foi concebida e articulada por Daniela B. O. Américo de Godoy, contando com a colaboração de Danilo Seithi Kato (UFTM), Erlon Honorato (CIMEAC) e Beatriz Vivian Schneider-Felicio (USP). Dentre os temas abordados, destacam-se: a instituição escolar como uma forma de colonialidade, a escola indígena como um projeto de escola específica, diferenciada e autônoma; as políticas públicas destinadas aos povos indígenas desde 1988; a resistência e resiliência dos povos indígenas, bem como sua necessidade de empoderamento técnico no trato com a sociedade envolvente; a interculturalidade radical como inter-epistemologia e intercientificidade.

Acredito que o panorama histórico e conceitual apresentado por Gersem possibilita uma ampliação (necessária) em relação à dimensão da interculturalidade presente nos currículos escolares. Destaco principalmente a sua defesa por uma Universidade Intercultural Indígena como um lugar capaz de articular horizontalmente diversos saberes e conhecimentos. Essa questão nos convida a refletir sobre os paradigmas educacionais vigentes sobretudo no Brasil, os quais tendem a operar por meio da segregação da sociedade em nãoindígenas e indígenas. A concepção indígena de "complementaridade de 
saberes" parece ser muito mais condizente com uma realidade multicultural e cabocla como a nossa, do que aquela pautada na lógica eurocêntrica, excludente e racista que ainda vigora como modelo de sociedade e, portanto, de educação.

O estudo documental de Marisol Uribe Pérez (UD, Colômbia) procede a uma análise rigorosa sobre artigos, teses e outros documentos relativos ao ensino de ciências e sua relação com a cultura, a partir de um enfoque intercultural crítico. Apresenta questões centrais a esse debate, destacando como conteúdos mais relevantes: o desafio de descolonizar o saber, a necessidade de romper com currículos monoculturais, o reconhecimento e valorização da alteridade, a compreensão de que a ciência é uma subcultura da cultura ocidental, o desenvolvimento da habilidade de cruzar fronteiras culturais (entre os conhecimentos ecológicos tradicionais e os conhecimentos científicos escolares). Também considera que o ensino de ciências orientado a partir deste enfoque deve reconhecer além das implicações da diversidade étnica, as de gênero, a linguística, assim como a diversidade acadêmica dos estudantes. Por fim, ressalta que o debate epistemológico nesse campo permite integrar as lógicas não clássicas com as lógicas da ciência ocidental.

O artigo de Nadenka Beatriz Melo Brito (UD, Colômbia) apresenta uma reflexão sobre cenários de educação intercultural, principalmente em relação à experiência do povo wayuu (Colômbia) perante uma proposta de etno-educação. A partir da concepção de que os povos originários produzem conhecimentos ecológicos tradicionais é proposto que os mesmos sustentem a base de uma relação de comunicação simétrica com a ciência ocidental, de modo que as especificidades educativas desses povos, pautadas na forma pela qual se relacionam com o território e com suas tradições, sejam respeitadas e incluídas no ensino por meio da negociação de argumentos oriundos de sistemas simbólicos distintos. Com isso, aponta a interculturalidade como uma alternativa ao cientificismo ocidental, ou seja, um meio de superar a exclusão epistêmica e o etnocentrismo.

O artigo de Wagner Mateus (UFAM) traz o ponto de vista de um intelectual indígena (baré) em relação à educação socioambiental no Brasil. A partir do perspectivismo ameríndio de Eduardo Viveiros de Castro analisa criticamente como a relação entre natureza e cultura, tal qual concebida pelos povos 
indígenas, pode contribuir para ultrapassar a "lógica especista" que sustenta a ideia eurocêntrica de que a espécie humana seria a mais importante do planeta. Em suas palavras: "a educação ambiental enquanto processo educativo que visa à formação da cidadania ambiental baseada no perspectivismo ameríndio e seus modus operandi de conviver biopoliticamente, não é outra, senão, uma forma de percepção do mundo, que não segue a norma 'branca' ocidental, um ato descolonizador de agir no mundo". Seu texto apresenta uma alternativa a práticas educacionais interculturais, na medida em que propõe um diálogo entre diferentes perspectivas cosmológicas.

Anatália Daiane de Oliveira (UFMT) e Marli Lúcia Tonatto Zibetti (Unir) apresentam os resultados de uma pesquisa etnográfica junto ao povo Puruborá, de Rondônia, que tratou de "investigar os processos históricos, movimentos sociais e políticos que possibilitaram a conquista da escola". O texto traz contribuições relevantes sobre o papel da escola para a garantia de uma série de direitos indígenas. No caso de um povo ressurgido como o Puroborá, o artigo aponta como as questões relacionadas ao território, à educação, à saúde, se articulam com a necessidade do reconhecimento étnico por parte do Estado. A escola aparece como importante meio de revitalização da cultura e da identidade indígena em situações em que o contato com o mundo não-indígena é uma realidade.

Leonardo Longhini (USP) durante sua pesquisa etnopsicológica realizada junto ao povo Terena da Terra Indígena Araribá (SP) questiona-se sobre o que, na esfera educacional, seria significativo para essa comunidade. Contrapondo a aprendizagem tradicional com o modelo proposto pela educação regular, reflete sobre as consequências de um contato cada vez mais intenso com a sociedade envolvente, sobretudo, no caso das aldeias mais urbanizadas. Apresenta como perspectiva recorrente a ideia de que a escola teria substituído de algum modo o papel de socialização e de transmissão cultural própria às famílias. Sublinha o conflito entre anciãos e jovens relativo ao não interesse desses em aprender a língua materna ensinada na escola da aldeia. Conclui com a proposta de que a atividade de "tradução cultural" (em relação à cultura ocidental) seria um mecanismo interessante para o estabelecimento de um diálogo intercultural, por 
se pautar na lógica indígena, ressalta que quando isso não ocorre as trocas tendem a ser desiguais, marcadas pela folclorização dos saberes indígenas.

O artigo de Luciana Gomes da Luz Silva (UFMG) apresenta um relato de experiência sobre os desafios relativos ao processo de institucionalização do curso de licenciatura intercultural indígena nesta universidade; abarcando tanto questões de ordem administrativas, quanto de ordem pessoal dos estudantes (manejo do dinheiro, necessidade de atendimento médico e odontológico, dentre outras). Um dos apontamentos mais interessantes é a secretaria como um lugar privilegiado de mediação entre estudantes indígenas, professores, outros estudantes e a comunidade universitária. Com muita sensibilidade, a autora aponta para a necessidade de compreender os modos pelos quais os estudantes indígenas se organizam quanto a suas demandas, dando destaque para 0 importante papel da liderança indígena. Por fim, sublinha que "a comunidade universitária deve estar preparada para receber esse público, uma vez que os indígenas vão se estabelecendo nesse espaço privilegiado do saber acadêmico, trazendo a riqueza da sua diversidade, das suas línguas e culturas, e, sobretudo, trazendo novos saberes".

Marina de Lima Tavares (UFMG), Juarez Melgaço Valadares (UFMG) e Célio da Silveira Júnior (UFMG) apresentam experiências curriculares vividas no Curso de Formação Intercultural para Educadores Indígenas da UFMG, na área de Ciências da Vida e da Natureza. Enfatizam que os professores dentro dessa habilitação "têm trabalhado os conteúdos de Física, Química e Biologia integrados por eixos temáticos, como instrumentos articuladores tanto das disciplinas entre si quanto na abertura do currículo para questões vivenciadas pelos professores indígenas em suas escolas”. Apontam como uma de suas principais preocupações a adequação do planejamento às questões (sociais, políticas e territoriais) próprias aos povos indígenas. Trata-se de uma importante contribuição no sentido de implicar todos os sujeitos envolvidos no processo de ensino a partir de situações-problema próprias à realidade desses sujeitos, incluindo aí o professor.

O artigo de Marília Xavier Cury (USP) apresenta situações de descolonização do museu etnográfico por meio da experiência vivida com os povos Kaingang, Terena e Guarani Nhandeva do oeste do estado de São Paulo. 
Ao tratar da participação indígena durante o processo de organização de comunicações museológicas a autora discute as possibilidades agentivas relativas ao exercício de apropriação simbólica dos museus, apontando o caráter político dessa empreita. No contexto de uma transformação dessa instituição, os museus se apresentam como uma arena interessante de diálogo, de rememoração e de ensino tanto para os povos indígenas quanto para a sociedade envolvente. Finaliza seu texto apontando para a necessidade de "os museus etnográficos buscarem qualidade comunicacional, tendo para isso que enfrentar a problemática comunicacional que se coloca em diálogo com os indígenas, em contato com as suas culturas e problemas existenciais, com a sua complexidade, em se tratando, principalmente, de outras visões de mundo, das práticas espirituais e ritualísticas e de outros saberes".

Por fim, fechando esse dossiê, Juliana Dal Ponte Tiveron (USP) e José Francisco Miguel Henriques Bairrão (USP) apresentam, a partir de uma escuta psicanalítica, uma análise do ensino Kaingang (T.I. Vanuíre) tal qual mantido pelo Grupo de Cultura Kaingang. Sugerem que um ensino de fato Kaingang não deve desvincular o cultural do espiritual sob pena da manutenção das subjugações históricas sofridas por esses povos. A interculturalidade apresentase aqui não tanto em função da adequação do outro a um modelo preliminar, no caso o escolar, mas em função da sanção de uma outra concepção de ensino, atrelada ao ser, ao corpo e à espiritualidade. Trata-se de uma contribuição relevante neste campo justamente por ampliar a perspectiva analítica para além dos muros das escolas.

Desejo que esse dossiê possa contribuir para o enriquecimento de debates sobre a educação intercultural no Brasil e na América Latina. Boa leitura a todos! 